\title{
PENGARUH MODEL PEMBELAJARAN PREDICT-OBSERVE- EXPLAIN TERHADAP PEMAHAMAN KONSEP IPA MAHASISWA PGSD UNIVERSITAS MUHAMMADIYAH SIDOARJO
}

\author{
Fitria Wulandari \\ wulandarifitria17@gmail.com \\ Pendidikan Guru Sekolah Dasar \\ Fakultas Keguruan dan Ilmu Pendidikan \\ Universitas Muhammadiyah Sidoarjo
}

\begin{abstract}
This research begins from the problems students of primary school teacher education Universitas Muhammadiah Sidoarjo which is low in developing their understanding on the concept of science. Students are still having difficulties when understanding the basic concept materials of science. The average midterm students exam score is 64.57. It is still less than 65. This research was conducted with the aim to know the influence of Predict-Observe-Explain learning model to understanding the concept of science of students. Based on this objective, this research uses experimental quantitative research design. Researchers use descriptive statistics with the type of experimental method used is One Group Pretest-Posttest Design. The instrument used by the researcher is a science comprehension concept test sheet. To test the hypothesis and answer the problem formulation of data analysis technique used is N-Gain test. The results showed that Predict-ObserveExplain learning model influenced the understanding of student science concept. It can be seen from the result of the average score before getting treatment by giving pretest about 66,28. Furthermore, after being given treatment by using PredictObserve-Explain model of learning PGSD students solve the Posttest problem by getting an average score of 83.14. Then the averages are used to identify the influence of the Predict-Observe-Explain model of learning on the understanding of the student science concept. From the result of $\mathrm{N}$-Gain value shows that its influence is 0,49 with medium criterion.
\end{abstract}

Keywords: predict-observe-explain learning model, understanding science, students of primary school teacher education.

\begin{abstract}
Abstrak: Penelitian ini berawal dari permasalahan mahasiswa S1 PGSD Universitas Muhammadiah Sidoarjo yang rendah dalam mengembangkan pemahamannya terhadap konsep IPA. Mahasiswa masih kesulitan pada saat memahami materi konsep dasar IPA. Adapun rata-rata nilai UTS mahasiswa sebesar 64,57. Hal tersebut masih kurang dari nilai 65. Penelitian ini dilakukan dengan tujuan untuk mengetahui pengaruh model pembelajaran Predict-Observe-Explain terhadap pemahaman konsep IPA Mahasiswa PGSD. Berdasarkan tujuan tersebut maka penelitian ini menggunakan rancangan penelitian kuantitatif ekperimen. Peneliti menggunakan statistik deskriptif dengan jenis metode ekperimen yang digunakan adalah One Group Pretest-Posttest Design. Instrument yang digunakan peneliti yaitu lembar tes pemahaman konsep IPA. Untuk menguji hipotesis dan menjawab rumusan masalah teknik analisis data yang digunakan yaitu uji $N$-Gain. Hasil penelitian menunjukkan bahwa model pembelajaran Predict-Observe-Explain berpengaruh terhadap pemahaman konsep IPA mahasiswa PGSD. Hal tersebut dapat dilihat dari hasil nilai rata-rata sebelum mendapatkan perlakuan dengan memberikan
\end{abstract}


Fitria, Pengaruh Model Pembelajaran Predict-Observe-Explain...

soal pretest sebesar 66,28. Selanjutnya setelah diberikan perlakuan dengan menggunakan model pembelajaan Predict-Observe-Explain mahasiswa PGSD menyelesaikan soal Posttest dengan mendapatkan nilai rata-rata sebesar 83,14. Kemudian nilai rata-rata tersebut digunakan untuk pengetahui besar pengaruh model pembelajaan Predict-Observe-Explain terhadap pemahaman konsep IPA mahasiswa PGSD. Dari hasil nilai N-Gain menunjukkan bahwa pengaruhnya sebesar 0,49 dengan kriteria sedang.

Kata Kunci: Model pembelajaran Predict-Observe-Explain, Pemahaman IPA, Mahasiswa PGSD.

\section{PENDAHULUAN}

Pendidikan yang terjadi dalam lingkungan sekolah sering disebut dengan pendidikan formal, karena sudah memiliki rancangan pendidikan berupa kurikulum tertulis yang tersusun secara sistematis, jelas, dan rinci, begitu juga dengan mahasiswa. Dalam pendidikan di universitas juga diperlukan peran seorang pendidik dalam hal ini adalah dosen sama seperti pada jenjang pendidikan sebelumnya. Peran seorang dosen adalah mengembangkan segala potensi yang dimiliki oleh seorang mahasiswa. Dosen di tingkat universitas tidak hanya mampu mentransfer ilmu pengetahuan kepada mahasiswa, melaikan juga harus mampu menumbuhkan perasaan senang dan mampu menjadi pembelajar.

Perasaan senang dan mampu menjadi pembelajar dapat menjadikan mahasiswa merasa tertantang untuk terus mengeksplorasi rasa ingin tahunya, sehingga akan terusmenerus mencoba, dan terpacu mengembangkan kemampuan dan keterampilannya dalam mempelajari materi dalam mata kuliah-mata kuliah.

Pada mata kuliah konsep dasar IPA Program Studi S1 PGSD Universitas Muhammadiyah Sidoarjo terdapat indikasi bahwa mahasiswa masih rendah dalam mengembangkan pemahamannya. Mahasiswa masih kesulitan pada saat memahami materi konsep dasar IPA. Hal tersebut dikarenakan mahasiswa belum terbiasa mengaplikasikan pengetahuan yang dimilikinya secara langsung, sehingga pemahaman mahasiswa dalam hal ini kurang berkembang. Pada dasarnya jika dosen memberikan kesempatan bagi mahasiswa pada proses pembelajaran untuk dapat mempraktikkan sendiri pemahamannya, maka mahasiswa tentunya akan lebih memahami dan dapat menerapkannya.

Pemahaman konsep adalah perbuatan yang tertanam dalam pikiran serta mempunyai makna sehingga mengerti pemahaman secara mental, implikasi maupun aplikasi dalam kehidupan sehari-hari. Anderson \& krathwohl menyebutkan bahwa terdapat 7 proses kognitif memahami diantaranya : a) Menafsirkan (interpreting), b) Memberikan contoh (examplifyng), c) Mengklasifikasikan (classifying), d) Me-ringkas (summarizeing), e) Menarik inferensi (infering), f) Membandingkan (comparing), dan g) Menjelaskan (explaining).

Pemahaman konsep IPA sangat penting dimiliki oleh mahasiswa agar tidak terjadi kesalahan dalam konsep IPA. Pemahaman konsep dapat dilakukan dengan 
Fitria, Pengaruh Model Pembelajaran Predict-Observe-Explain...

melaksanakan perkuliahan yang melibatkan mahasiswa secara aktif, dengan melibatkan mahasiswa secara aktif dalam kegiatan perkuliahan akan mendorong mereka untuk melakukan eksplorasi terhadap materi perkuliahan. Mahasiswa akan lebih mudah memahami konsep dari materi yang akan disampaikan dengan pengalaman belajar secara langsung.

Berdasarkan hasil observasi dokumen, rendahnya pemahaman mahasiswa dapat dilihat dari hasil nilai pemahaman mahasiswa pada saat UTS. Rata-rata nilai UTS mahasiswa sebesar 64,57. Hal tersebut masih kurang dari nilai 65 .

Menurut Prof. Dr. Bedjo Sujanto, M.Pd keberhasilan pembelajaran banyak ditentukan oleh tingkat kualitas proses pembelajaran. Semakin baik proses pembelajaran, maka akan menghasilkan produk yang semakin baik. Sehingga dosen perlu menerapkan model pembelajaran yang dapat mengembangkan pemahaman mahasiswa tentang konsep IPA. Menurut Joyce \& Weil, model pembelajaran adalah suatu rencana atau pola yang dapat digunakan untuk membentuk kurikulum (rencana pembelajar-an jangka panjang), merancang bahan-bahan pembelajaran, dan membimbing pembelajaran dikelas atau yang lain.

Salah satu model pembelajaran yang dapat melibatkan mahasiswa dan dapat menumbuhkan kegairahan belajar dalam proses belajar secara aktif adalah pembelajaran dengan model pembelajaran Predict-Observe-Explain.

Indrawati \& Setiawan (2009) menyebutkan bahwa model pembelajaran PredictObserve-Explain adalah suatu strategi pembelajaran dimana pendidik dapat mengali pemahaman peserta didik dengan cara meminta mereka untuk melaksanakan tiga tugas utama, yaitu predik, observasi, dan memberikan penjelasaan (Explain). White dan Gustone (1992), menyatakan bahwa POE ( Predict, Observe, Explain) merupakan model pembelajaran yang bersifat efektif untuk memperoleh serta meningkatkan konsep sains peserta didik.

Berdasarkan permasalahan tersebut peneliti tertarik untuk mengetahui pengaruh model pembelajaan Predict-Observe-Explain terhadap pemahaman konsep IPA mahasiswa PGSD.

\section{METODE}

Penelitian ini dilakukan dengan tujuan untuk mengetahui pengaruh model pembelajaran Predict-Observe-Explain terhadap pemahaman konsep IPA Mahasiswa PGSD. Berdasarkan tujuan tersebut maka penelitian ini menggunakan rancangan penelitian kuantitatif ekperimen. Dalam penelitian ini peneliti bermaksud untuk menimbulkan suatu kejadian atau keadaan, yang kemudian diteliti bagaimana pengaruhnya.

Peneliti menggunakan statistik deskriptif karena peneliti hanya ingin mendeskripsikan data sampel, serta hanya untuk mengetahui perbedaan nilai antara nilai pretest dengan nilai posttest mahasiswa. Adapun jenis metode ekperimen yang 
Fitria, Pengaruh Model Pembelajaran Predict-Observe-Explain...

digunakan adalah One Group Pretest-Posttest Design. One Group Pretest-Posttest Design adalah suatu model yang menerapkan pretest sebelum diberikan perlakuan dan memberikan posttest sesudah diberikan perlakuan.

Dengan diberikan perlakuan tersebut maka data yang akan didapat akan lebih akurat. Karena dapat membandingkan data hasil sebelum diberikan perlakuan dan hasil sesudah diberikan perlakuan. Adapun gambaran desain penelitian ini Menurut Sugiyono (2017) adalah sebagai berikut:

$\mathrm{O} 1 \mathrm{X} \mathrm{O} 2$

\section{Keterangan :}

O1 : Pretest (sebelum diberikan perlakuan)

O2 :Posttest (setelah diberikan perlakuan model pembelajaran Predict-Observe-

\section{Explain)}

X :Diberikan perlakuan dengan menerapkan model pembelajaran Predict-ObserveExplain.

Subjek dalam penelitian ini adalah mahasiswa PGSD kelas B1 Semester 2 yang berjumlah 35 mahasiswa, yang terdiri dari 6 mahasiswa laki-laki dan 29 mahasiswa perempuan.

Instrumen yang digunakan peneliti yaitu lembar tes pemahaman konsep IPA. Sebelum digunakan dalam penelitian ini lembar tes pemahaman konsep IPA tersebut telah divalidasi oleh ahli. Adapun teknik pengumpulan data dalam yang digunakan adalah teknik tes, yang terdiri dari tes awal (Pretest) dan tes akhir (Posttest). Teknik tes tersebut digunakan untuk mengetahui nilai hasil perkulahan mahasiswa PGSD.

Untuk menguji hipotesis dan menjawab rumusan masalah teknik analisis data menggunakan uji N-Gain. Hal tersebut karena dalam penelitian ini hanya menggunakan stu kelompok saja. Adapun rumus normal gain menurut Meltzer (2002) (dalam Yanti, 2014) sebagai berikut:

$$
\frac{=\text { SKOR POSTTSET }- \text { SKOR PRETEST }}{\text { SKOR IDELA }- \text { SKOR PRETEST }}
$$

Sedangkan rumusan masalah besar pengaruh peneliti menggunakan table kriteria pengaruh. Hake (1999) (dalam Yanti, 2014) mengkategorisasi nilai peningkatan berdasarkan N-Gain tersebut yaitu:

Table 3.1

Kriterian Pengaruh N-Gain

\begin{tabular}{|l|l|}
\hline \multicolumn{1}{|c|}{ Nilai N-Gain } & \multicolumn{1}{c|}{ Kriteria } \\
\hline$<0,3$ & Rendah \\
\hline $0,3-0,7$ & Sedang \\
\hline$>0,7$ & Tinggi \\
\hline
\end{tabular}


Fitria, Pengaruh Model Pembelajaran Predict-Observe-Explain...

Kriteria di atas digunakan peneliti untuk mengetahui kriteria pengaruh dari hasil penelitian. Jika N-Gain kurang dari 0,3 maka kriteria tersebut tergolong pada kriteria rendah. jika $\mathrm{N}$-Gain 0,3 sampai 0,7 maka kriteria $\mathrm{N}$-Gain sedang. Dan jika nilai $\mathrm{N}$-Gain lebih dari 0,7 maka tergolong kriteria tinggi.

\section{HASIL DAN PEMBAHASAN}

Pada bagian ini sebelum memberikan perlakuan pada siswa, peneliti terlebih dahulu melakukan observasi dua kali. Hal tersebut dilakukan untuk mengetahui permasalahan yang ada pada mahasiswa PGSD kelas B1 Semester 2. Kemudian setelah mengetahui permasalahan yang ada di kelas tersebut peneliti selanjutnya peneliti melakukan perkuliahan dengan mengunakan model pembelajaran Predict-ObserveExplain.

Pengambilan data dalam penelitian ini dilakukan selama dua minggu. Adapun teknik pengumpulan data dalam penelitian ini dengan memberikan mahasiswa soal tes pemahaman konsep IPA Pretest dan Posttest. Berikut tabel data nilai hasil Pretest mahasiswa sebelum diberikan perlakuan.

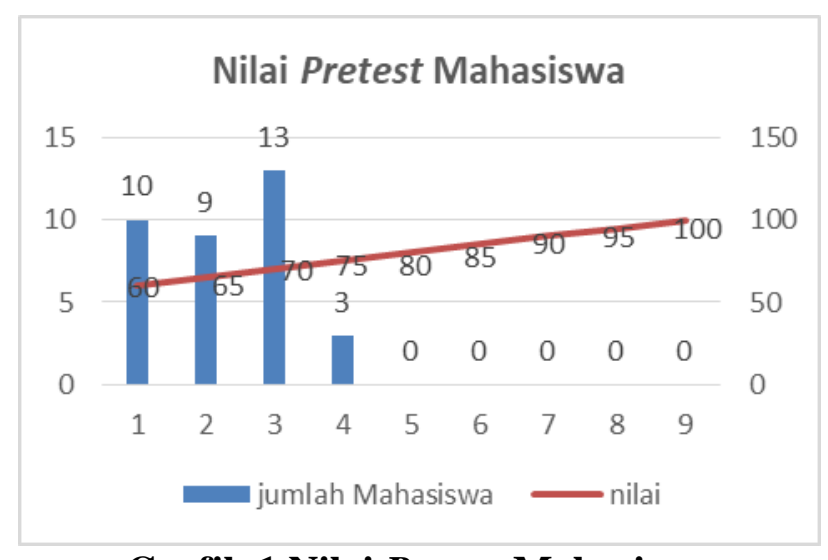

Grafik 1 Nilai Pretest Mahasiswa

Dari grafik di atas menunjukkan nilai pretest mahasiswa. Mahasiswa yang mendapatkan nilai 60 sebanyak 10 mahasiswa, nilai 65 sebanyak 9 mahasiswa, nilai 70 sebanyak 13 mahasiswa, dan nilai 75 sebanyak 3 mahasiswa.

Dari nilai pretest tersebut peneliti selanjutnya menghitung rata-rata hasil pretest dengan menjumlah nilai pretest masing-masing mahasiswa dibagi jumlah mahasiswa. Hasil dari menghitung rata-rata tersebut yaitu sebesar 66,28.

Peneliti selanjutnya menghitung prosentase dari hasil nilai pretest mahasiswa. Hasil perhitungannya yaitu sebanyak 28,57\% mahasiswa yang mendapatkan nilai 60 . Sebanyak $25,71 \%$ mahasiswa yang mendapatkan nilai 65 . Sebanyak $37,14 \%$ mahasiswa yang mendapatkan nilai 70 , dan sebanyak $8,57 \%$ mahasiswa yang mendapatkan nilai 75 . 
Fitria, Pengaruh Model Pembelajaran Predict-Observe-Explain...

Setelah pemberian pretest peneliti memberikan perlakuan kepada mahasiswa. Perlakuan yang diberikan peneliti dengan menerapakan model pembelajaran PredictObserve-Explain pada perkuliahan konsep darar IPA. Setelah pemberian perlakuan peneliti memberikan soal Posttest untuk mengetahui nilai mahasiswa setelah diberikan perlakuan. Berikut tabel data nilai hasil Posttes mahasiswa sebelum diberikan perlakuan.

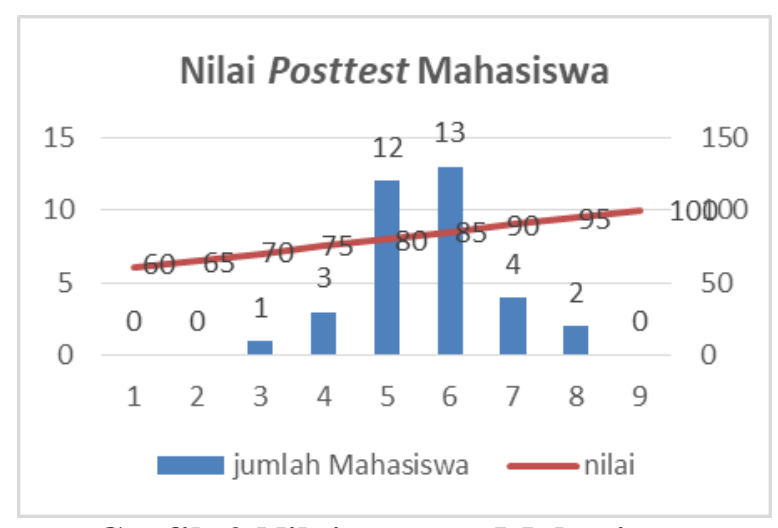

Grafik 2 Nilai Posttest Mahasiswa

Dari grafik diatas menunjukkan nilai posttest mahasiswa. Mahasiswa yang mendapatkan nilai 70 sebanyak 1 mahasiswa, nilai 75 sebanyak 3 mahasiswa, nilai 80 sebanyak 12 mahasiswa, nilai 85 sebanyak 13 mahasiswa, nilai 90 sebanyak 4 mahasiswa, dan nilai 95 sebanyak 2 mahasiswa. Dari nilai posttest tersebut peneliti selanjutnya menghitung rata-rata hasil posttest dengan menjumlah nilai posttest masing-masing mahasiswa dibagi jumlah mahasiswa. Hasil dari menghitung rata-rata tersebut yaitu sebesar 83,14.

Selanjutnya peneliti menghitung prosentase dari hasil nilai posttest mahasiswa. Hasil perhitungannya yaitu sebanyak 2,857\% mahasiswa yang mendapatkan nilai 70 . Sebanyak $8,57 \%$ mahasiswa yang mendapatkan nilai 75 . Sebanyak $34,28 \%$ mahasiswa yang mendapatkan nilai 80 . Sebanyak 37,14\% mahasiswa yang mendapatkan nilai 85 . Sebanyak 11,42\% mahasiswa yang mendapatkan nilai 90, dan sebanyak 5,7\% mahasiswa yang mendapatkan nilai 95 .

Setelah data nilai pretest dan posttest diperoleh peneliti kemudian menguji pengaruh dari perlakuan yang telah dilaksanakan dengan menggunakan rumus uji NGain. Berikut ini akan disajikan hasil uji pengaruh.



Diagram 1 Jumlah Mahasiswa 
Fitria, Pengaruh Model Pembelajaran Predict-Observe-Explain...

Dari diagram lingkaran di atas menunjukkan bahwa jumlah mahasiswa yang mendapatkan nilai $\mathrm{N}$-Gain 0,2 sebanyak $11 \%$. Mahasiswa yang mendapatkan nilai $\mathrm{N}$ Gain 0,3 sebanyak $9 \%$. Mahasiswa yang mendapatkan nilai N-Gain 0,4 sebanyak $14 \%$. Mahasiswa yang mendapatkan nilai N-Gain 0,5 sebanyak 26\%. Mahasiswa yang mendapatkan nilai N-Gain 0,6 sebanyak 20\%. Mahasiswa yang mendapatkan nilai NGain 0,7 sebanyak $11 \%$. mahasiswa yang mendapatkan nilai $\mathrm{N}-$ Gain 0,8 sebanyak $9 \%$.

Adapun kriteria tingkat pengaruh model pembelajaran Predict-Observe-Explain terhadap pemahaman konsep IPA mahasiswa PGSD dapat dilihat pada diagram berikut ini:

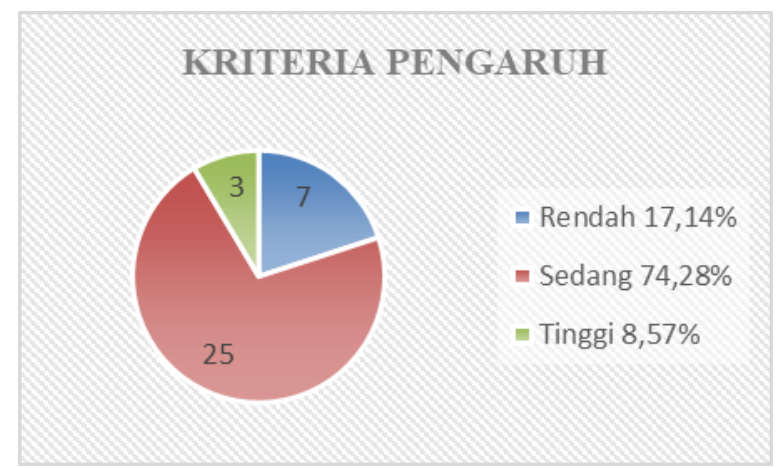

Diagram 2 Kriteria Pengaruh

Dari diagram di atas menunjukkan bahwa terdapat 7 mahasiswa dengan kriteria rendah, 25 mahasiswa dengan kriteria sedang dan 3 mahasiswa dengan kriteria tinggi. Untuk pengaruh Predict-Observe-Explain terhadap pemahaman konsep IPA mahasiswa PGSD secara keseluruhan sebesar 0,49 termasuk dalam kriteria sedang.

\section{SIMPULAN}

Berdasarkan hasil penelitian di atas maka dapat disimpulkan bahwa model pembelajaran Predict-Observe-Explain berpengaruh terhadap pemahaman konsep IPA mahasiswa PGSD. Hal tersebut dapat dilihat dari hasil nilai rata-rata sebelum mendapatkan perlakuan dengan memberikan soal pretest sebesar 66,28 . Selanjutnya setelah diberikan perlakuan dengan menggunakan model pembelajaan Predict-ObserveExplain mahasiswa PGSD menyelesaikan soal Posttest dengan mendapatkan nilai ratarata sebesar 83,14. Kemudian nilai rata-rata tersebut digunakan untuk pengetahui besar pengaruh model pembelajaan Predict-Observe-Explain terhadap pemahaman konsep IPA mahasiswa PGSD. Dari hasil nilai N-Gain menunjukkan bahwa pengaruhnya sebesar 0,49 dengan kriteria sedang.

\section{SARAN}

Penerapan model pembelajaran sangat penting dalam proses perkuliahan, karena fungsi model pembelajaran adalah sebagai pedoman bagi seorang pendidik dalam 
Fitria, Pengaruh Model Pembelajaran Predict-Observe-Explain...

pelaksanaan proses pembelajaran. Salah satu nya yang dapat digunakan sebagai inovasi yaitu model pembelajaran Predict-Observe-Explain.

\section{DAFTAR RUJUKAN}

Indrawati \& Setiawan, Wanwan. 2009. Pembelajaran Aktif, Kreatif, Efektif, dan Menyenangkan untuk Guru SD. Jakarta: PPPPTK IPA.

Lorin W. Anderson \& David R. Krathwohl.2010. Pembelajaran, Pengajaran, dan Asesmen. Yogyakarta : Pustaka Pelajar.

Rusman. 2012. Model-Model Pembelajaran Mengembangkan Profesionalisme Guru. Bandung : PT RAJAGRAFINDO PERSADA.

Sugiyono. 2017. Metode Penelitian Pendidikan (Pendekatan Kuantitatif, Kualitatif, dan $(R \& D)$. Bandung : ALFABETA.

Trianto. 2007. Model Pembelajaran Inovatif Berorientasi Konstruktivistik. Jakarta: Tim Prestasi Pustaka.

White and Gustone. 1992. Probling Understanding. Hongkong : Graficraft Typosetters Ltd.

Yanti, Herianti. 2014. Tanya Jawab Seputar Penelitian Pendidikan Sains. Jakarta:Universitas Syarief Hidayatullah. 